\title{
A Research on the Relationship between FDI and Jiangsu's Regional Economy Disparity
}

\author{
Baoqian Wang, Cheng Wang \\ Business School, Hohai University, Nanjing, China \\ Email: Bq64@163.com, hhucwangcheng@126.com
}

Received May 8, 2012; revised June 18, 2012; accepted June 25, 2012

\begin{abstract}
Through reading and summarizing relevant articles, the authors analyze two different kinds of effects that FDI influence the regional economy. Location and digesting ability reflects such non-equilibrium. By using regression analysis, the authors discover, in south Jiangsu, which the unit FDI increase contributes most to the GDP development, with middle and north Jiangsu lagging behind. The regression coefficient is $1.198,0.429$ and 0.572 respectively. Considering the index of digestion ability, unit FDI increase and unit GDP contribution rate still share strong relevant relationship. However, the coefficients change. The effects that FDI stimulate GDP growth are weakened, been made up by the endogenous ability. The granger test shows that in south Jiangsu, there exists a cycle of accumulative effect, namely both the FDI increase and the GDP growth do well with each other. However, in the rest of Jiangsu province, such effect is not obvious. Considering the elements of location and digesting ability, this paper offers tactics for Jiangsu for a better coordinate of future development.
\end{abstract}

Keywords: FDI; Non-Equilibrium; Regional Economy Disparity; Digestion Ability

\section{Introduction}

With the development of global economy, the economic tide among countries becomes tighter than any other periods of time before, and FDI (Foreign Direct Investment) has become a quite useful tool for developing countries or regions to develop their economy. Since China adopts the policy of reform and opening up, FDI has been one of the most important elements of stimulating its economy. As a province in east China, especially near Shanghai, Jiangsu province possess a unique edge in bringing in FDI, namely the tremendous market potential and better investment environment. Making use of FDI has been one of the engines for Jiangsu's economy growth. In the year of 2000, the GDP in Jiangsu province was 8404.57 hundred million RMB. In 10 years, such number roared up to 34741.2 hundred million RMB with a growth rate near $313.61 \%$. Accompany with the growth of GDP was the increase of the amount of FDI absorption, from 64.24 hundred million dollars up to 253.23 hundred million dollars with a growth percentage of 393.19.

However, the problem of non-equilibrium becomes more serious thus will damage the coordinate development. By dividing Jiangsu province into three main parts or regions, it is easy to find out the facts that different parts bring in different number of FDI, which shows the non-equilibrium absorption, while the growth of GDP in three regions also reflects this trend. The south Jiangsu develops much faster than the other parts of Jiangsu province.

By analyzing the series statistics from the year of 2000 to 2009 , the empirical test intends to discover whether the FDI widens the gap between the north middle and south Jiangsu.

\section{Literature Review}

Both domestic and overseas academicians made large amounts of researches about the positive effects that FDI brought to the economic development for the targeted countries. DeMello (1996, 1997, 1999): FDI will stimulate the output of the targeted countries whether the targeted countries was relied on the leader or following the leaders considering the technical conditions [1]. Berthelemy (2000), Demurger (2000): the effects that FDI imposed to the economic growth were more influential than domestic capital storage [2]. Hossein Jalilian, John Weiss (2002): FDI does help to stimulate the economy growth of the targeted countries, and at the same time, such help is proportional to the educational level [3]. Cheng Hsiao (2002): by using the methods of VaR, Cheng Hsiao analyses china and other 23 developing countries and gets the conclusion that GDP and FDI interact with each other. The relationship is kind of mutual furtherance [4].

Most researchers discovered the positive effects that FDI brought to the targeted countries; however, when 
considering the non-equilibrium of FDI, we could realize the negative effects. Wei Houkai (2002): through analyzing the FDI statistics from 1985 to 1999 , Wei got the conclusion that $90 \%$ of the reason which resulted in the development gap between east and west china was owed to the FDI [5]. Li Yurong (2005): less developed countries should first digest overseas FDI and then learn to breakthrough and to innovate, and only in this way can those countries get substantial development [6].

Above all, the non-equilibrium of FDI is manifested into two aspects, namely the non-equilibrium of choosing locations and the non-equilibrium of digestion ability. At first, FDI is a kind of capital chasing after profit. Before their investment activity, investors will take lots of elements into consideration including market and its competitions, opportunities, factor costs, infrastructures and the government motivations. Areas differ with each other in the above elements, so different areas reflect different competitive advantages which are important indexes for investors. Areas with stronger advantages tend to bring in more FDI. Because of the existence of the positive effects of FDI, it's obvious to understand that such nonequilibrium in location choice is one of the most influential factors that result in the disparity of regional economy. Secondly, although the advanced technology and managerial expertise is helpful for the development of the economic growth of the targeted areas, such positive effects never work on their own. The ability of the targeted areas to digest the FDI determines the extent of exertion of FDI. During the process of digestion, the storage and the quality of human resource in the targeted countries and innovation ability is of vital importance.

\section{Region Division}

This paper divide Jiangsu province into three regions namely "S.": south Jiangsu (the city of Nanjing, Suzhou Wuxi, Changzhou and Zhenjiang), "M.": middle Jiangsu (the city of Yangzhou Taizhou and Nantong) and "N.": north Jiangsu (the city of Huai'an, Yancheng, Xuzhou, Lianyungang and Suqian).

According to the yearbook of Jiangsu province (20002009) [7], we have got Table 1 to summary the FDI amount that Jiangsu brought in the last ten years. In the last ten years, the number of FDI absorption grew significantly, from 6.424 billion dollars in 2000 up to 25.323 billion dollars in 2009 , with an accumulative increase percentage of $294.19 \%$. South Jiangsu represents tremendous competitive edges in bringing in FDI, accounting for nearly $60 \%$ of the total, leaving middle and north Jiangsu lagging behind. Such distribution shows the non-equilibrium in the process of bringing in FDI.

Such non-equilibrium is also magnificent in the digestion ability of FDI. P. M. Romer viewed human resource as one important element in production, and took human resource into production function, hence strictly defined the human resource. P. M. Romer defined human resource as the final results which were related to the personal knowledge, understanding and abilities. The results came from formal education and professional trainings. It's the human being's wisdom that forms the ground of absorption ability. As a result, this paper adopts the number of university graduates and intermediate technicians as index to evaluate the quantity and quality of the human resource in three regions together with the innovation ability.

From Table 2 it is clear that the number of university graduates and intermediate technicians is larger than middle and north Jiangsu, especially for university graduates, the number is even larger than the sum of the middle and north Jiangsu. South Jiangsu has the most of education resources with lots of universities and research institutes. The overall level of education is higher than the rest Jiangsu. Otherwise, the industry economy is better than the rest Jiangsu, possessing developed industrialized cities like Suzhou, Wuxi and Changzhou. As a result, the absorption ability of south Jiangsu is stronger which not only reflects but also results in the non-equilibrium.

Table 1. FDI absorption amount and percentage in separate regions.

\begin{tabular}{cccccccc}
\hline & Total & S. & M. & N. & S.\% & M.\% & N.\% \\
\hline 00 & 64.24 & 56.27 & 3.12 & 4.85 & 87.59 & 4.86 & 7.55 \\
01 & 71.21 & 62.27 & 3.96 & 4.98 & 87.44 & 5.56 & 7.00 \\
02 & 103.69 & 91.18 & 6.75 & 5.76 & 87.94 & 6.51 & 5.55 \\
03 & 158.02 & 133.75 & 15.15 & 9.12 & 84.64 & 9.59 & 5.77 \\
04 & 121.38 & 92.04 & 21.54 & 7.80 & 75.83 & 17.75 & 6.42 \\
05 & 131.80 & 98.68 & 25.14 & 7.98 & 74.87 & 19.07 & 6.06 \\
06 & 174.31 & 123.58 & 39.94 & 10.79 & 70.90 & 22.91 & 6.19 \\
07 & 218.91 & 147.97 & 47.43 & 23.51 & 67.59 & 21.67 & 10.74 \\
08 & 251.20 & 168.02 & 54.01 & 29.17 & 66.89 & 21.50 & 11.61 \\
09 & 253.23 & 174.14 & 44.69 & 34.40 & 68.77 & 17.65 & 13.58 \\
\hline
\end{tabular}

Unit: hundred million dollars; statistics came from the yearbook of Jiangsu province (online version) [8].

Table 2. Number of university graduate (A) and intermediate technicians (B).

\begin{tabular}{ccccccc}
\hline \multirow{2}{*}{ Year } & \multicolumn{2}{c}{ South } & \multicolumn{2}{c}{ Middle } & \multicolumn{2}{c}{ North } \\
\cline { 2 - 7 } & A & B & A & B & A & B \\
\hline 2001 & 5.34 & 40.21 & 1.14 & 14.33 & 1.05 & 18.97 \\
2002 & 8.03 & 41.23 & 1.05 & 14.69 & 1.95 & 23.62 \\
2003 & 8.76 & 49.09 & 1.46 & 16.75 & 3.43 & 24.95 \\
2004 & 13.47 & 51.39 & 2.36 & 17.94 & 3.92 & 26.27 \\
2005 & 16.23 & 52.23 & 2.77 & 18.24 & 3.97 & 25.06 \\
2006 & 18.50 & 59.48 & 2.97 & 25.53 & 4.26 & 28.26 \\
2007 & 23.16 & 64.49 & 4.40 & 26.83 & 5.84 & 29.23 \\
2008 & 29.56 & 65.67 & 5.06 & 24.15 & 6.48 & 30.32 \\
2009 & 29.06 & 68.95 & 5.23 & 25.58 & 6.99 & 31.23 \\
\hline
\end{tabular}

Unit: ten thousand; statistics came from the yearbook of Jiangsu province (online version) [9]. 


\section{Economy Development}

The overall economic development of Jiangsu province ranks high in china, and it is one of the FDI clusters in china. But it is still facing the problem of development non-equilibrium. This paper uses GDP as an index to measure the development situation of Jiangsu regional economy.

From the statistics in Table 3, it's easy to discover that the total GDP amount in south Jiangsu is bigger than middle and north Jiangsu. Region comparison (north =1) also reflects the facts that both south/north index and middle/north index are increasing. The gap between the south and north is becoming larger as well as the gap between the middle and north.

If we combine the current development situation and FDI non-equilibrium (absorption and digestion ability) together, it is not difficult to discover the following facts:

First, in the process of developing GDP of Jiangsu province and its regional economy, FDI absorption grows correspondingly. Take south Jiangsu as example, south Jiangsu absorbs more than $60 \%$ of the total FDI amount of the whole province, at the same time, its GDP also covers around $60 \%$ of the total GDP of Jiangsu province.

Second, with the non-equilibrium of FDI, the gap between the three regions becomes much larger. In the terms of development level, south Jiangsu is apparently higher than rest Jiangsu. For middle Jiangsu, it also reflects such trend, that with more FDI absorption than north Jiangsu recent years, it's GDP growth and growth rate is faster than the north part.

The above analysis is based on specific statistics, and the following part of this paper will make use of the above statistics to do the empirical analysis in order to discover more substantial relationship between FDI absorption and Jiangsu's regional economy disparity.

\section{Empirical Analysis}

\subsection{Statistics Illustration}

The statistics of this paper is from "the year book of Jiangsu
(2000-2009)", and part of the statistics comes from the government online information.

In order to use the same unit of currency RMB, this paper exchanges dollars into RMB by using the exchange rate of 6.49 (the middle exchange rate at May 31, 2011).

The regression analysis is done by the software of SPSS17.0, while the unit test and granger test are done by the software of EVeiws6.0 [11].

\subsection{Model Foundation}

Establish a linear regression model to estimate variable $\mathrm{FDI}_{i}$ and parameter $\theta_{\mathrm{FDI}_{i}}$. This model deprives from C-D production function by taking its logarithmic form and making it the linear form, indicating FDI to be a very important element that pulls the development of GDP. The former labor and capital element in C-D function are viewed as solid variables. We put labor, capital and the former solid parameter together as a new solid parameter which is defined as $\alpha_{i}$. The model is as follows:

$$
\ln Y_{i}=\alpha_{i}+\theta_{\mathrm{FDI}_{i}} \ln \mathrm{FDI}_{i}+\varepsilon_{i} \quad(i=1,2,3)
$$

$Y_{i}(i=1,2$, and 3$)$ : the output of the three regions in Jiangsu evaluated by the GDP index. 1-south Jiangsu, 2-middle Jiangsu, 3-north Jiangsu;

$\alpha_{i}$ : labor, capital and the former solid parameter together as a new solid parameter;

$\mathrm{FDI}_{i}$ : the amount that three regions absorb FDI;

$\theta_{\mathrm{FDI}}:$ parameter of sensitivity;

$\varepsilon_{i}$ : residuals.

\subsection{Empirical Results and Analysis}

From Table 4, we could find out that the relationship between regional growth and the bringing in of FDI is magnificent and notable. The Pearson correlation is $0.899,0.934$ and 0.958 respectively. However by analyzing its coefficient we could further discover that, on one hand FDI stimulates the growth of economy, but on the other hand, FDI expand the gap of the three parts. In south Jiangsu, the coefficient is 1.198 , which means one

Table 3. GDP of the three regions and the percentage.

\begin{tabular}{|c|c|c|c|c|c|c|c|}
\hline & S. & M. & N. & S.\% & M.\% & N.\% & Region comparison $\left(\mathrm{N}_{.}=1\right)$ \\
\hline 00 & 4814.84 & 1613.81 & 1975.92 & 57.29 & 19.20 & 23.51 & $2.44 / 0.82 / 1$ \\
\hline 01 & 5446.25 & 1764.73 & 2186.94 & 57.95 & 18.78 & 23.27 & $2.49 / 0.81 / 1$ \\
\hline 02 & 6280.10 & 1950.86 & 2436.90 & 58.87 & 18.29 & 22.84 & $2.58 / 0.80 / 1$ \\
\hline 03 & 7821.58 & 2233.97 & 2715.81 & 61.24 & 17.49 & 21.25 & $2.88 / 0.82 / 1$ \\
\hline 04 & 9591.77 & 2719.39 & 3220.08 & 61.76 & 17.51 & 20.73 & $2.98 / 0.84 / 1$ \\
\hline 05 & 11417.34 & 3216.36 & 3610.76 & 62.58 & 17.63 & 19.79 & $3.16 / 0.89 / 1$ \\
\hline 06 & 13485.61 & 3860.78 & 4235.70 & 62.49 & 17.89 & 19.62 & $3.18 / 0.91 / 1$ \\
\hline 07 & 15931.09 & 4625.59 & 4976.23 & 62.39 & 18.12 & 19.49 & $3.20 / 0.93 / 1$ \\
\hline 08 & 18506.16 & 5477.62 & 5931.61 & 61.86 & 18.31 & 19.83 & $3.12 / 0.92 / 1$ \\
\hline 09 & 21154.19 & 6390.12 & 7196.89 & 60.89 & 18.39 & 20.72 & $2.94 / 0.89 / 1$ \\
\hline
\end{tabular}

Unit: hundred million RMB; Statistics came from the yearbook of Jiangsu province (online version) [10]. 
Table 4. Results of correlation analysis.

\begin{tabular}{lccc}
\hline & South Jiangsu & Middle Jiangsu & North Jiangsu \\
\hline Pearson correlation & 0.899 & 0.934 & 0.958 \\
Coefficient & 1.198 & 0.429 & 0.572 \\
T value & 5.818 & 7.403 & 9.489 \\
$\mathrm{R}^{2}$ adjustment & 0.785 & 0.857 & 0.908 \\
\hline
\end{tabular}

unit of FDI will results in 1.198 unit of GDP growth in the logarithmic form; In middle Jiangsu, the coefficient is 0.429 , which means one unit of FDI will results in 0.429 unit of GDP growth in the logarithmic form; In north Jiangsu, the coefficient is 0.572 , which means one unit of FDI will results in 0.572 unit of GDP growth in the logarithmic form.

If the three regions absorb the same amount of FDI, the outcome will be quite different considering the above three coefficients. South Jiangsu benefits most from the FDI absorption, the next is north Jiangsu while middle Jiangsu benefits the least. Anyhow, the situation is that south Jiangsu absorb nearly $60 \%$ of the total FDI in Jiangsu province, such non-equilibrium location will increasingly expand the gap among the three regions. The non-equilibrium location is contributed to the different competitive edges of the three regions which are merely hard to reverse in the short run, so such location will show a stable trend. In addition to the internal accumulation effects, such non-equilibrium location will make it worse on the basis of the current gaps.

Given the regression relationship between the non- equilibrium FDI and the regional economy development, this paper does the granger test to research the interactive force of the two elements hence to offer helps for the future suggestions.

Granger pointed out that any judgment would be useless unless the statistics were integration numbers. Following his theory, before the granger test, it's necessary to do the unit root test in order to make sure the statistics are integration ones [12].

From Table 5, we get the answer that on 5\% level $\Delta^{2}$ lnGDP and $\Delta^{2}$ lnFDI are integrated. So $\Delta^{2} \operatorname{lnGDP}$ and $\Delta^{2} \operatorname{lnFDI}$ are available to do the granger causality test. The result of causality test is as follows.

According to the Table 6, in south Jiangsu, both two hypotheses are rejected. As a result, the granger causality exits between the $\Delta^{2} \operatorname{lnGDP}$ and $\Delta^{2} \ln F D I$ in south Jiangsu. That means in this region, the growth of FDI and GDP are mutually interactive with each other. For the absorption of FDI, the GDP of south Jiangsu gets increased, contrarily, the growth of GDP enhances its advantages in bringing in FDI that will be helpful for south Jiangsu to better absorbing FDI, which is called the cycle of accumulative effects. In middle Jiangsu, the test accepts the hypothesis of " $\Delta^{2} \ln$ GDP does not granger cause $\Delta^{2} \operatorname{lnFDI}$ ", which means in middle Jiangsu the growth of GDP doesn't significantly pull the growth of FDI for the reason that the cycle of accumulative effects is still not established yet. However, for north Jiangsu, both two hypothesizes are accepted, and the interactive effect is not notable.

Table 5. ADF unit root test.

\begin{tabular}{|c|c|c|c|c|c|}
\hline & Variable & $\mathrm{ADF}$ & $1 \%$ & $5 \%$ & $10 \%$ \\
\hline \multirow{6}{*}{ South } & $\operatorname{lnGDP}$ & 14.47553 & -2.847250 & -1.988198 & -1.600140 \\
\hline & $\Delta \operatorname{lnGDP}$ & -0.163189 & -2.886101 & -1.995865 & -1.599088 \\
\hline & $\Delta^{2} \ln G D P$ & -0.209885 & -2.937216 & -2.006292 & -1.598068 \\
\hline & $\operatorname{lnFDI}$ & 1.576557 & -2.847250 & -1.988198 & -1.600140 \\
\hline & $\Delta \operatorname{lnFDI}$ & -2.221052 & -2.886101 & -1.995865 & -1.599088 \\
\hline & $\Delta^{2} \operatorname{lnFDI}$ & -3.514412 & -2.937216 & -2.006292 & -1.598068 \\
\hline \multirow{6}{*}{ Middle } & $\operatorname{lnGDP}$ & 13.95236 & -2.847250 & -1.988198 & -1.600140 \\
\hline & $\Delta \operatorname{lnGDP}$ & 0.343656 & -2.886101 & -1.995865 & -1.599088 \\
\hline & $\Delta^{2} \ln G D P$ & -2.235080 & -2.937216 & -2.006292 & -1.598068 \\
\hline & $\operatorname{lnFDI}$ & 2.313476 & -2.847250 & -1.988198 & -1.600140 \\
\hline & $\Delta \operatorname{lnFDI}$ & -1.027905 & -2.886101 & -1.995865 & -1.599088 \\
\hline & $\Delta^{2} \operatorname{lnFDI}$ & -2.767925 & -2.937216 & -2.006292 & -1.598068 \\
\hline \multirow{6}{*}{ North } & $\operatorname{lnGDP}$ & 14.64485 & -2.847250 & -1.988198 & -1.600140 \\
\hline & $\Delta \operatorname{lnGDP}$ & 0.621010 & -2.886101 & -1.995865 & -1.599088 \\
\hline & $\Delta^{2} \ln G D P$ & -4.848631 & -2.937216 & -2.006292 & -1.598068 \\
\hline & $\operatorname{lnFDI}$ & 2.387482 & -2.847250 & -1.988198 & -1.600140 \\
\hline & $\Delta \operatorname{lnFDI}$ & -1.623939 & -2.847250 & -1.988198 & -1.600140 \\
\hline & $\Delta^{2} \operatorname{lnFDI}$ & -3.291327 & -2.886101 & -1.995865 & -1.599088 \\
\hline
\end{tabular}


Table 6. Granger causality test results.

\begin{tabular}{|c|c|c|c|c|}
\hline Hypothesis & Lags & F-statistics & Prob. & Judgments \\
\hline \multicolumn{5}{|c|}{ South Jiangsu } \\
\hline$\Delta^{2} \ln$ GDP does not granger cause $\Delta^{2} \ln \mathrm{FDI}$ & 2 & 5.56320 & 0.2872 & Refuse \\
\hline$\Delta^{2} \operatorname{lnFDI}$ does not granger cause $\Delta^{2} \ln$ GDP & 2 & 12279.2 & 0.0064 & Refuse \\
\hline \multicolumn{5}{|c|}{ Middle Jiangsu } \\
\hline$\Delta^{2} \ln$ GDP does not granger cause $\Delta^{2} \ln \mathrm{FDI}$ & 1 & 1.37805 & 0.3056 & Accept \\
\hline$\Delta^{2} \operatorname{lnFDI}$ does not granger cause $\Delta^{2} \ln$ GDP & 1 & 3.90072 & 0.1195 & Refuse \\
\hline$\Delta^{2} \operatorname{lnGDP}$ does not granger cause $\Delta^{2} \ln \mathrm{FDI}$ & 2 & 0.9276 & 0.5921 & Accept \\
\hline$\Delta^{2} \operatorname{lnFDI}$ does not granger cause $\Delta^{2} \ln$ GDP & 2 & 0.68382 & 0.6499 & Accept \\
\hline
\end{tabular}

\section{Conclusions and Suggestions}

According to the empirical analysis, it's easy to discover the conclusion that for all three regions, the positive effect that FDI brings to GDP growth is notable and magnificent. Hence in making regional economy policies, we should make full use of such positive effects to stimulate regional economy development.

While the government is actively bringing in FDI, it should balance the coordination development of all three regions, offer more favorable policies to middle and north part, and hence reverse the exist non-equilibrium. South Jiangsu should emphasis on the quality and structure of FDI, combine FDI absorption and the update of industry structure together to serve for its economy transition, not just for merely duplication investment. Middle and north Jiangsu should recognize the gap in terms of the competitive advantages and together with its reasons, grasp the opportunity of developing coastal areas, update industry structure and investment environment, and bring in FDI that fits its industry features and environment features.

The mechanism of by using FDI to improve economy is an internal process that integrates foreign investment into domestic competitive edges. By merely bring in FDI in the long run will supplant domestic investment and make one region lose its economic autonomy, which is not good to the substantial and healthy development. All three parts in Jiangsu should concentrate on digestion and application, take advantage of the spillover effect of FDI, and learn relatively advanced technology and management expertise to improve self-competitiveness. For south Jiangsu, it shares a relatively higher level of development and stronger research and development power, as a result, it could appropriately increase the threshold of FDI making the learning process a long and dynamic process to provide a steady stream of power for regional growth. On the other hand, for middle and north Jiangsu, to cooperate with universities and institutes in south $\mathrm{Ji}$ angsu will be helpful in bringing in FDI. The following ways are available to strengthen human resource training as well as innovation consciousness such as union colleges, union labs (institutes), and bases integrated "industry-learning-research" and research institutes stationed in development zones etc.

\section{REFERENCES}

[1] X. Han, "A Research on the Relationship between FDI and the Development of Jiangsu Province," Modern Business Trade Industry, No. 11, 2008, pp. 102-104.

[2] Z. Wang and Y. J. Gu, "The Positive Impacts of Foreign Direct Investment on China's Economic Development," Journal of Kunming University of Science and Technology, No. 5, 2005, pp. 41-45.

[3] J. Weiss and H. Jalilian, "Industrialization in an Age of Globalization: Some Comparisons between East and South East Asia and Latin America," Oxford Development Studies, Vol. 32, No. 2, 2004, pp. 283-307. doi:10.1080/13600810410001699993

[4] H. Cheng, "Panel Data Analysis-Advantages and Challenges," Test, Vol. 16, No. 1, 2007, pp. 1-22.

[5] H. K. Wei, "Effects of Foreign Direct Investment on Regional Economic Growth in China," Economic Research, Vol. 4, 2002, pp. 19-25.

[6] Y. R. Li, "FDI Spillover Effects and the Development Exploit of Developing Countries," Contemporary Economic Research, Vol. 12, 2005, pp. 40-42.

[7] The Yearbook of Jiangsu Province (Online Version). http://www.jssb.gov.cn/jstj/tjsj/tjnj.htm

[8] The Yearbook of Jiangsu Province (Online Version). http://www.jssb.gov.cn/jstj/jsnj/2001/nj19/nj1901.htm

[9] The Yearbook of Jiangsu Province (Online Version). http://www.jssb.gov.cn/jstj/jsnj/2002/nj14.htm

[10] The Yearbook of Jiangsu Province (Online Version). http://www.jssb.gov.cn/jstj/jsnj/2001/nj19.htm

[11] X. T. Zhang, "EViews Guidebook and Cases," China Machine Press, Beijing, 2007.

[12] D. L. Mo, "Doing Unit Root Test by SPSS Software," Journal of Hezhou University, No. 25, 2009, pp. 133-140. 